\title{
Zooplanktivory in the Baltic Sea: a comparison of prey selectivity by Clupea harengus and Mysis mixta, with reference to prey escape reactions
}

\author{
Markku Viitasalo $^{1, *}$, Juha Flinkman ${ }^{2}$, Maiju Viherluoto ${ }^{1,3}$ \\ ${ }^{1}$ Department of Ecology and Systematics, Division of Hydrobiology, PO Box 17, 00014 University of Helsinki, Finland \\ ${ }^{2}$ Finnish Institute of Marine Research, PO Box 33, 00931 Helsinki, Finland \\ ${ }^{3}$ Tvärminne Zoological Station, 10900 Hanko, Finland
}

\begin{abstract}
We investigated prey selection by the 2 most important planktivores in the northern Baltic, the Baltic herring Clupea harengus membras L. and the mysid shrimp Mysis mixta Lilljeborg. We hypothesised that the intensity of prey selection by herring is positively related to prey size and that deviations from this relationship can be explained by prey escape capabilities. For the non-visually hunting mysids we assumed that prey size is less important than in herring and that escape capabilities of the prey explain a larger fraction of selectivities. To evaluate these hypotheses, we obtained selectivity indices for $C$. harengus membras and $M$. mixta from previous studies made either in the field (herring) or in the laboratory (mysids). We then quantified the escape performances of the 5 most abundant crustacean zooplankton species in the Baltic Sea by videofilming the plankters escaping from an artificially created water flow (siphon). As hypothesized, herring behaved as size-selective predators: prey selectivity rank was Temora longicornis $>$ Eurytemora affinis $>$ Pseudocalanus elongatus > Acartia sp. > Bosmina longispina maritima. In M. mixta, the selectivity rank was surprisingly similar, only the cladoceran $B$. longispina maritima was relatively more positively selected than in herring. Comparing the observed predator selectivities with the results of the siphon experiments allowed us to identify cases where the predators appeared to show 'true' positive selection for a certain prey (E. affinis) and where the selection was 'truly' negative ( $P$. elongatus). On the basis of these results we suggest that large-sized copepods are important food for both herring and mysids and that a hydrography-induced shift towards a cladoceran-dominated zooplankton community may decrease the food gain by Baltic herring.
\end{abstract}

KEY WORDS: Prey selection · Escape reactions · Clupea harengus $\cdot$ Mysis mixta $\cdot$ Mesozooplankton · Baltic Sea

Resale or republication not permitted without written consent of the publisher

\section{INTRODUCTION}

In the aquatic environment, it is not prey abundance but rather the encounter rate between predator and prey that determines prey availability for a predator. The encounter rate depends on 3 factors, namely prey concentration, prey detection distance and the velocity difference between predator and prey (Gerritsen \&

*E-mail: markku.viitasalo@helsinki.fi
Strickler 1977). For visually hunting planktivorous predators, prey detection distance is directly related to prey visibility, which is a function of prey size (Brooks \& Dodson 1965, Gardner 1981, Wetterer 1989, Luo et al. 1996), pigmentation (Zaret 1972, Zaret \& Kerfoot 1975, Buskey 1994, Tsuda et al. 1998) and behaviour (O'Brien et al. 1976, Williamson 1980, Zaret 1980, Yen \& Strickler 1996). The non-visually hunting invertebrate predators, in turn, need to use hydrodynamic or olfactory cues to detect the prey (e.g. Strickler 1975). In contrast to the visual cues, the hydrodynamic distur- 
bance produced by zooplankters may not be directly related to their body size. The non-visually hunting predators may therefore detect fast swimming or abruptly jumping small prey from a longer distance than they detect slowly swimming larger prey (see Tiselius et al. 1997).

The active and passive predation-avoidance mechanisms of prey also greatly affect the outcome of the predatory interaction. The escape abilities of various zooplankton species have been demonstrated with many predator types, ranging from carnivorous copepods, cladocerans, jellyfish and mysids (Yen \& Fields 1992, Browman et al. 1989, Suchman \& Sullivan 1998, Viitasalo et al. 1998, respectively) to various fish species (e.g. Drenner et al. 1978, Drost et al. 1988, Heath 1993). Most zooplankton species can detect an approaching predator from the hydrodynamical disturbance it creates (Singarajah 1969, Strickler 1975) and attempt to escape before or during the attack, either by displaying a strong leap (e.g. Browman et al. 1989) or a 'dead-man response' (Kerfoot 1978). Also, after capture morphological defences such as spines may still make the predator reject the prey (e.g. Dodson 1974, Barnhisel 1991).

Thus, prey 'selection' is the end product of all components of the predation cycle, i.e., search, encounter, approach, attack and handling (Holling 1959, Gerritsen \& Strickler 1977, Kerfoot 1978). Selectivity indices that show prey ingestion rates in relation to prey availability (e.g. Chesson 1978, Pearre 1982) present the end result of the whole interaction, and can thus be used to evaluate the 'vulnerability' (Pastorok 1981) of different prey types. However, to know why a certain prey species is more vulnerable to predation than another, we need to obtain accurate estimates of escape performances of each prey species, and to relate these to the observed selectivities. However, few studies have attempted to explain predator selectivities with independently quantified prey escape capabilities. A better understanding of the different components of the predation cycle will help us to estimate in which cases prey ingestion rates can be predicted from encounter rates, and in which cases the interaction is complicated by the predation-avoidance mechanisms of the prey.

Natural or anthropogenic changes in trophic status and hydrographical conditions of the sea may significantly influence the zooplankton community structure. For instance, in the North Sea (e.g. Aebischer et al. 1990, Fransz et al. 1991) and the Baltic Sea (Segerstråle 1969, Vuorinen \& Ranta 1987, Lumberg \& Ojaveer 1991, Viitasalo et al. 1995b) many zooplankton taxa have been shown to display strong long-term variations in connection with hydrography and climate. Flinkman et al. (1998) have also suggested that these hydrography-driven variations in zooplankton availability may have contributed to variations in herring growth in the northern Baltic Sea. One of our main objectives was therefore to verify which zooplankton species are the most easily caught, and which are the most difficult species to catch by Baltic planktivores. On the basis of this information we wanted to estimate the effects of changes in zooplankton communities on 'food availability' for these predators.

With these objectives in mind we investigated prey selection by the 2 most important planktivores in the northern Baltic, the Baltic herring Clupea harengus membras L. (hereafter referred to as 'herring') and the mysid shrimp Mysis mixta Lilljeborg. We hypothesised that the intensity of prey selection by herring is positively related to prey size (Blaxter \& Hunter 1982, Flinkman et al. 1992) and that deviations from this relationship can be explained by prey escape capabilities. For mysids, that mainly hunt for zooplankton in the night by using mechanoreception (Mauchline 1980, Rudstam et al. 1989), we assumed that prey visibility is less important than for herring, and that prey escape capabilities may therefore explain a larger fraction of the observed selectivities. To evaluate these hypotheses we obtained selectivity indices for Baltic herring and M. mixta from previous studies made either in the field (herring) or in the laboratory (mysids). We then quantified the escape performances of the 5 most abundant crustacean zooplankton species in the Baltic Sea against an artificially created water flow. This allowed us to evaluate the selectivity patterns of herring and mysids in light of prey escape responses.

\section{MATERIALS AND METHODS}

Selectivity in Clupea harengus membras. The herring selectivity data are from Flinkman et al. (1998). The material, consisting of herring stomach samples and simultaneously taken zooplankton samples, was collected in the northern Baltic Proper and western Gulf of Finland in August 1985 and 1991. The fish were caught with a research trawl hauled between 10 and $30 \mathrm{~m}$ depths, on 4 to 6 consecutive nights at 4 different stations. Each station consisted of 2 or 4 trawl sites located $10 \mathrm{n}$ miles apart; 170 fish were analysed in 1985 and 200 in 1991. The total length of the fish selected for stomach-content analysis varied from 15 to $17 \mathrm{~cm}$ and their age from 2 to $6 \mathrm{yr}$.

Plankton samples were taken using 2 different methods. In 1985, all plankton samples were taken with a $100 \mu \mathrm{m}$ mesh WP-2 net: 3 vertical hauls (from $25 \mathrm{~m}$ to the surface) were taken before and 3 after each trawl haul. In 1991, both vertical and horizontal samplings 
were employed. Horizontal samples were taken by attaching 3 'nackthai' plankton samplers $(100 \mu \mathrm{m}$ mesh) to the trawls. A Student's $t$-test indicated no significant difference between the zooplankton sampling methods. For more details on sampling see Flinkman et al. (1998).

One hundred plankters were identified from each herring stomach and plankton sample, and a chisquare-test-based selectivity index, $V$ (Pearre 1982), was calculated using the average abundance percentages for each size category in stomachs and in respective plankton samples. The $V$-index is a useful measure of prey selection because, in contrast to many other indices, it is zero-valued for no selection, is fairly robust as regards the effect of rare species in the community, and is statistically testable (cf. Boyd 1976, Lechowicz 1982, Pearre 1982). The $V$-indices were then compared with the body size of the prey species. From the predator's perspective, prey 'size' is mainly a function of the profile area of the prey (e.g. O'Brien et al. 1976). However, as we had no data on the profile area of each prey, we chose to use wet weight (from Hernroth 1985 and Viitasalo 1992) as an index of prey size. We assume that the wet weight is a better approximation of prey size than, e.g., prey length, which varies greatly according to the length of appendages (such as furca in copepods). Also, as we were interested in the hydrodynamic disturbance created by different-sized prey, we wanted to use a measure more directly related to the body volume of the plankters than body length. For more details on analyses see Flinkman et al. (1998).

Selectivity in Mysis mixta. The mysid selectivity data are from an experimental study by Viherluoto \& Viitasalo (2001a). The material was collected in June to October 1998 from an open-sea area in the western Gulf of Finland (depth 65 to $80 \mathrm{~m}$ ). Mysids were collected with a $500 \mu \mathrm{m}$ mesh net (diameter $0.8 \mathrm{~m}$ ) and zooplankton with a $100 \mu \mathrm{m}$ mesh net (diameter $0.6 \mathrm{~m}$ ) by vertical hauls from near bottom to the surface. After sampling the mysids and zooplankton were put in separate insulated containers filled with seawater and transported ashore into a temperature-controlled room $\left(13^{\circ} \mathrm{C}\right.$, light:dark cycle of 16:8 h). Mysids were identified, transferred into a $10 \mathrm{l}$ aerated container with $0.2 \mu \mathrm{m}$ filtered seawater, and acclimated to the laboratory conditions without food for $\sim 24 \mathrm{~h}$. The zooplankton were kept in the transport container in natural seawater with aeration.

The experiments were conducted in 1.18 l glass bottles with 1 mysid in each. To determine prey selectivity at different prey concentrations, the mysids were provided 4 or 5 different dilutions (with 3 to 6 replicates) of the zooplankton mixture $(0.5 x$ to $15 x)$. A nominal ' $1 \times$ ' concentration was set to $\sim 20$ copepods $\mathrm{l}^{-1}$, which is a normal concentration in the study area in summer (Viitasalo et al. 1995b). The bottles containing the mysids and the prey were placed on a plankton wheel rotating at $0.5 \mathrm{rpm}$ for $12 \mathrm{~h}$, of which $8 \mathrm{~h}$ was in darkness. The experiment was ended by pouring the mysids and zooplankton onto a $50 \mu \mathrm{m}$ sieve and preserving with acid Lugol's solution. The numbers of prey remaining in the bottles was counted microscopically, and the selectivity index $V$ was calculated for each mysid as for the herrings, by comparing the ingestion rates of different prey with their percentage availability in the prey community (Pearre 1982).

The selectivity indices on a certain prey taxon varied substantially between the experiments done in different seasons and with different-sized mysids (Viherluoto \& Viitasalo 2001a). The data reported here represent average selectivity indices on crustacean zooplankton (copepods and cladocerans) for all mysids tested during the 5 experiments made in June to October 1998 (102 mysids, body lengths varying from 3 to $19 \mathrm{~mm}$ ). The selectivity indices should therefore be taken as rough estimates of overall preference of the whole Mysis mixta population.

Experiments with artificial flow. To investigate the escape capabilities of the most abundant prey taxa, we videofilmed adults or large juveniles of 4 copepod species (Acartia sp., Eurytemora affinis, Pseudocalanus elongatus, Temora longicornis) and 1 cladoceran species (Bosmina longispina maritima) escaping from suction created by a siphon. The data are those of Viitasalo \& Rautio (1998) and Viitasalo et al. (1998) supplemented with new data on P. elongatus. A Pasteur pipette was fixed vertically into a 11 Plexiglas aquarium and connected to a silicon tube hanging outside the aquarium; this created a suction of water to which the zooplankters reacted. To enable measurements of distances in 3 dimensions, 2 video cameras were fixed at right angles to the aquarium, the 2 images were combined onto 1 monitor with a digital image mixer, and the images were recorded with a videocassette recorder (resolution 50 frames $\mathrm{s}^{-1}$ ). Four parameters-escape position, escape speed, total escape distance, and escape success-were determined for each escape with an image-analysing program (Viitasalo et al. 1998). To quantify the flow field created by the siphon, we added almost neutrally buoyant phytoplankton particles to the water and measured their speeds when approaching the pipette. By noting the reaction distances of the zooplankton species within this flow field, we determined the threshold fluid velocity gradient $\left(\mathrm{s}^{-1}\right)$, which induced an escape reaction in each escaping plankter. Because the fluid flow may be disturbed close to the pipette body, only escapes that took place below the level of the opening of the pipette were taken into account. Further, in 


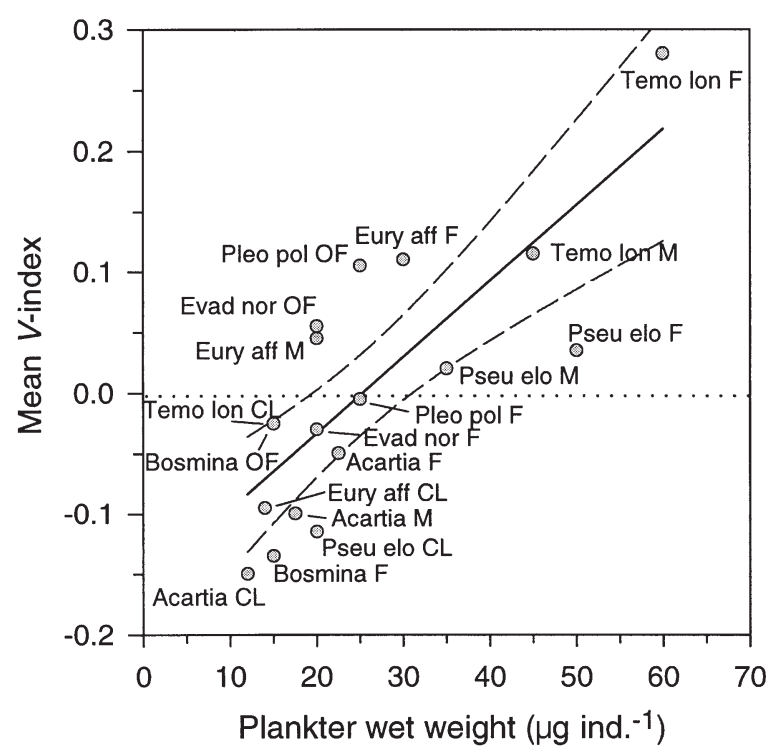

Fig. 1. Clupea harengus membras. Selectivity indices, $V$, for 18 most abundant prey species/stages found in herring stomachs plotted against prey wet weight. Values above horizontal dotted line indicate positive selection, those below line negative selection. Continuous line indicates significant linear regression $(y=-0.1593+0.006296 x)$ between the data sets, dashed lines indicate $95 \%$ confidence limits. Data collected in the Archipelago Sea, northern Baltic Sea, in 1985 and 1991 (Flinkman et al. 1998). Acartia: Acartia sp.; Bosmina: Bosmina longispina maritima; Eury aff: Eurytemora affinis; Evad nor: Evadne nordmanni; Pleo pol: Pleopsis polyphemoides; Pseu elo: Pseudocalanus elongatus; Temo lon: Temora longicornis. CL: large copepodite; F: female; M: male; OF: egg-carrying female

cases where a plankter performed several sequential jumps (between which the flow repeatedly drew the plankter towards the pipette), only the first escape was taken into account. The escape success of the plankters was, in turn, determined as a percentage of 'interactions' that ended in a successful escape. An interaction was defined as beginning when a plankter was for the first time entrained in the flow, and ending when the plankter was captured by the siphon or was able to escape farther away from the pipette mouth and continued to swim freely around.

\section{RESULTS}

\section{Selectivity in Clupea harengus membras}

The herring behaved as size-selective predators. There was a statistically significant positive correlation between plankter wet weight and the average selectivity index $V$ (Pearson correlation coefficient $r=0.79$, $\mathrm{p}=0.0001, \mathrm{n}=18)$. The large-sized Eurytemora affinis females, Temora longicornis adults and egg-carrying Pleopsis polyphemoides were the most positivelyselected taxa, whereas the copepodite stages of Acartia sp., E. affinis and Pseudocalanus elongatus, as well as Acartia sp. males and Bosmina longispina maritima females were negatively selected (Fig. 1).

We analysed the predatory interactions between herring and their prey by determining which prey species deviated most from the selection-wet weight regression line in Fig. 1. Table 1 shows the magnitude of these residuals for each prey taxa. The species and stages with the most positive residuals (i.e. egg-carrying Pleopsis polyphemoides and Evadne nordmanni, and Eurytemora affinis adults) were either poor escapers or were 'truly selected' by herring, regardless of their size and escape capabilities. The species with the most negative residuals (Pseudocalanus elongatus, Acartia sp. and the non-ovigerous Bosmina longispina maritima) were either good escapers, or were actively avoided by herring. It must be noted that these results are sensitive to departures from the linear hypothesis, and need to be interpreted with caution. However, we concluded that the small cladocerans were actively selected when they carried conspicuous eggs, and that 2 copepod taxa, Acartia sp. and P. elongatus, were more negatively selected by herring than predicted by their size.

Table 1. Clupea harengus membras. Deviations from the linear regression between prey wet weight and herring prey selectivity index, $V$ (Fig. 1). Positive value indicates that the taxon was more positively selected by herring than predicted by its size, negative value indicates the opposite. OF: egg-carrying female; F: female; M: male; CL: large copepodite; *values outside $95 \%$ confidence limits (see Fig. 1). Data presented in order of decreasing selectivity

\begin{tabular}{|lr}
\hline Species, stage & $\begin{array}{r}\text { Deviation fro } \\
\text { linear regress }\end{array}$ \\
\hline Pleopsis polyphemoides, OF & $0.107^{*}$ \\
Evadne nordmanni, OF & $0.088^{*}$ \\
Eurytemora affinis, F & $0.080^{*}$ \\
Eurytemora affinis, M & $0.078^{*}$ \\
Temora longicornis, F & 0.062 \\
Bosmina longispina maritima, OF & 0.040 \\
Temora longicornis, CL & 0.040 \\
Evadne nordmanni, F & 0.003 \\
Pleopsis polyphemoides, F & -0.003 \\
Temora longicornis, M & -0.009 \\
Eurytemora affinis, CL & -0.024 \\
Acartia sp., F & -0.032 \\
Pseudocalanus elongatus, M & -0.041 \\
Acartia sp., M & $-0.051^{*}$ \\
Acartia sp., CL & $-0.066^{*}$ \\
Bosmina longispina maritima, F & $-0.070^{*}$ \\
Pseudocalanus elongatus, CL & $-0.082^{*}$ \\
Pseudocalanus elongatus, F & $-0.120^{*}$ \\
\hline
\end{tabular}




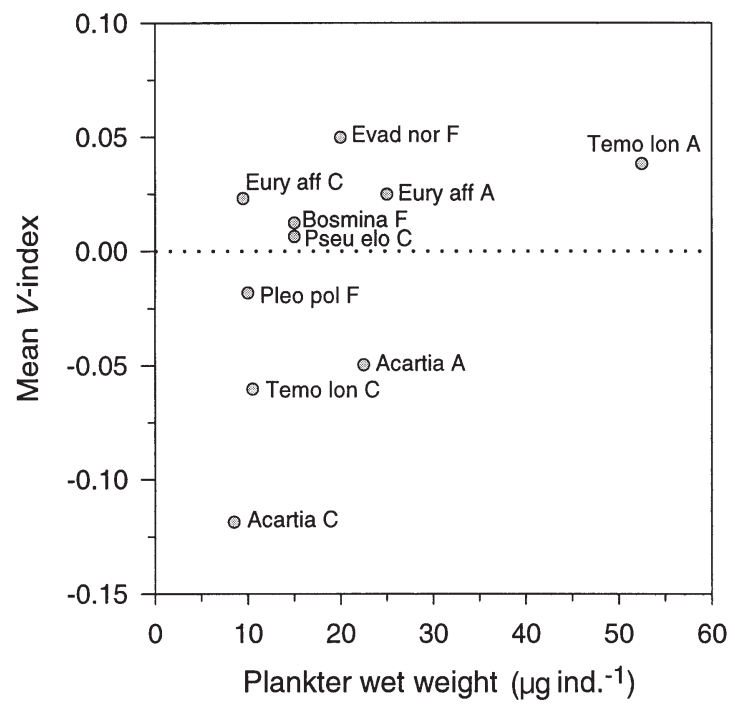

Fig. 2. Mysis mixta. Selectivity indices, $V$, for 10 most abundant prey species/stages, plotted against prey wet weight. Data from experimental study in 1998 with mysids collected at Hanko Peninsula, SW coast of Finland (Viherluoto \& Viitasalo 2001a). Values above horizontal dotted line indicate positive selection, those below line negative selection. Abbreviations as in Fig. 1

\section{Selectivity in Mysis mixta}

Mysis mixta were not clearly size-selective in their feeding (Fig. 2), i.e., there was no significant correlation between plankter wet weight and the mean $V$ index (Pearson $\mathrm{r}=0.47, \mathrm{p}=0.172, \mathrm{n}=10$ ). However, while there was a large scatter on the lower end of prey wet weights, the largest prey items (Evadne nordmanni, Eurytemora affinis and Temora longicornis adults) had the highest selectivity indices. Only Acartia sp. adults were clearly more negatively selected than could be expected from their size (Fig. 2).

The selectivity indices of mysids were generally much lower (varying from -0.12 to 0.05 ) than those of herring. This was probably due to averaging the indices over several seasons, during which both prey size (Viitasalo et al. 1995a) and mysid size (Viherluoto et al. 2000) varied substantially.

\section{Herring selectivity versus mysid selectivity}

To determine any similarities between herring and mysid selection, we plotted the selectivity indices of Mysis mixta against those of herring (Fig. 3). This showed that, e.g., adult Eurytemora affinis and Temora longicornis were positively selected, and Acartia sp. copepodites and adults and T. longicornis copepodites negatively selected by both predators. However, the

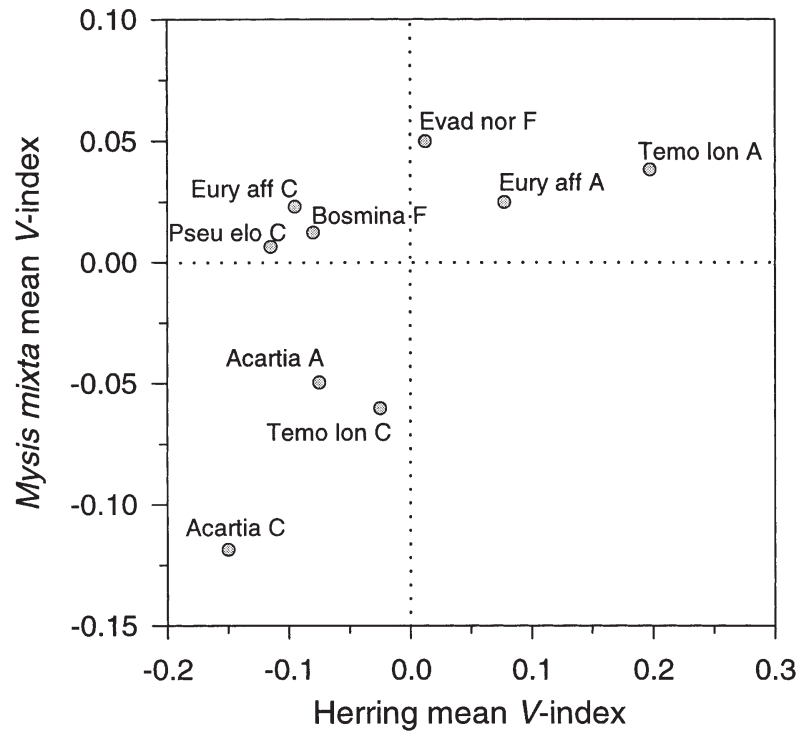

Fig. 3. Clupea harengus membras and Mysis mixta. Selectivity indices of mysids plotted against those of herring (data from Figs. $1 \& 2$ ). For herring, means for female and male copepods were used. Data points in lower left and upper right corners indicate similar selectivity by herring and mysids

correlation between the selection indices was not significant (Pearson $\mathrm{r}=0.56, \mathrm{p}=0.119, \mathrm{n}=9$ ), mainly because the selectivities for $E$. affinis copepodites, Pseudocalanus elongatus and Bosmina longispina maritima were different.

\section{Zooplankton escape responses with artificial flow}

The escape capabilities of Acartia sp. adults, Eurytemora affinis females, Pseudocalanus elongatus copepodites/adults, Temora longicornis adults and Bosmina longispina maritima females were tested against water flow created with a siphon. Fig. 4 shows all escape locations of the copepod species relative to the pipette. When only the escapes below the opening of the pipette were taken into account, the mean reaction distances of copepods were 0.52 and $0.53 \mathrm{~cm}$ for Acartia sp. and E. affinis, and $0.35 \mathrm{~cm}$ for both $P$. elongatus and T. longicornis. However, because the fluid velocities varied slightly between experiments, the corresponding average fluid-velocity gradients inducing an escape were 3.9, 5.4, 10.4 and $14.2 \mathrm{~s}^{-1}$ for Acartia sp., E. affinis, $P$. elongatus and $T$. longicornis, respectively (Table 2). There was large variation in the data, but, based on the mean fluid-velocity gradients eliciting escapes (Fig. 5: dotted lines), we ranked the 4 copepod species from the most 'alert' to the least 'alert' as follows: Acartia sp. $\approx$ E. affinis $>P$. elongatus $>T$. longi- 

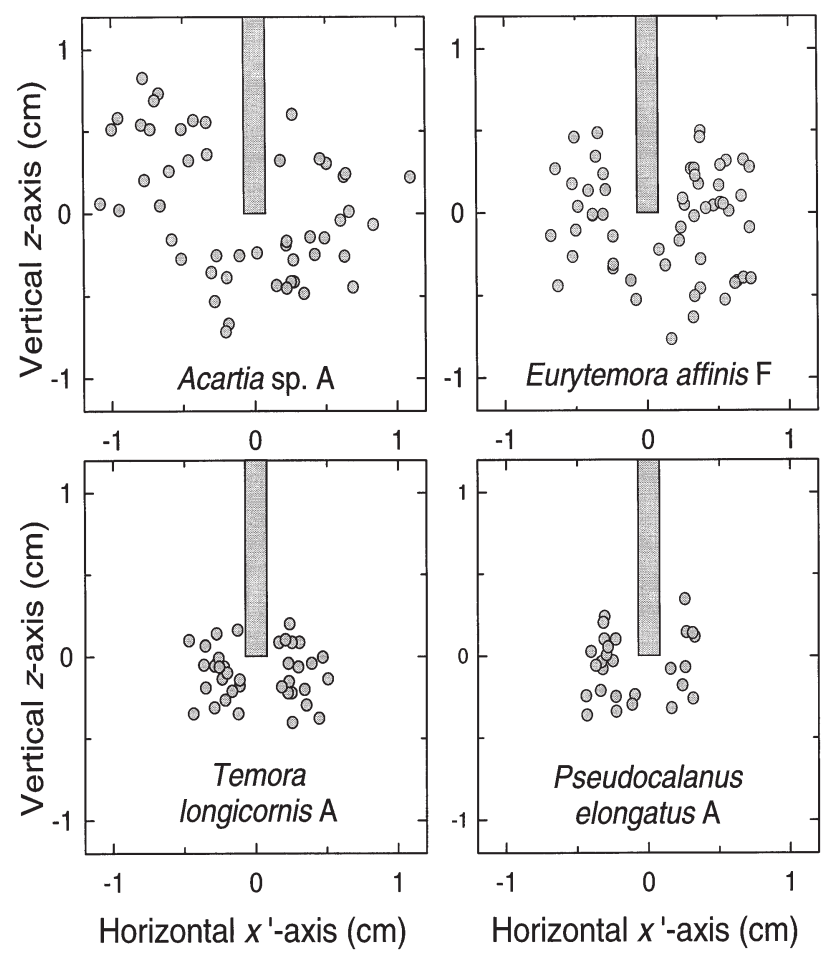

Fig. 4. Zooplankton escape experiment with artificial flow, showing escape locations of Acartia sp., Eurytemora affinis, Temora longicornis and Pseudocalanus elongatus relative to pipette siphoning water out of the experimental aquarium. Pipette is denoted by the shaded bar; opening of the pipette is at the origin of the coordinates. Third dimension (second horizontal axis, $y$ ) has been removed by projecting all escape points onto the $x$-z-plane (see Viitasalo et al. 1998)

cornis. The cladoceran B. longispina maritima did not show an escape response and was always captured by the siphon if entrained in the flow. This may however reflect its weak swimming abilities rather than its low hydrodynamical sensitivity.

Table 2. Zooplankton escape experiment with artificial flow. Mean $( \pm$ SD) copepod reaction distances and corresponding thresholds for fluid-velocity gradient, escape speeds during the first $0.06 \mathrm{~s}$ of escape, and total escape distances. Data include only escapes below level of opening of the pipette (see Fig. 4)

\begin{tabular}{|c|c|c|c|c|}
\hline Species (stage) & $\begin{array}{l}\text { Threshold } \\
\text { fluid velocity } \\
\text { gradient }\left(\mathrm{s}^{-1}\right)\end{array}$ & $\begin{array}{l}\text { Escape speed } \\
\quad\left(\mathrm{cm} \mathrm{s}^{-1}\right)\end{array}$ & $\begin{array}{l}\text { Total escape } \\
\text { distance } \\
(\mathrm{cm})\end{array}$ & $\mathrm{n}$ \\
\hline Acartia sp. (adults) & $3.94 \pm 5.05$ & $4.05 \pm 2.10$ & $0.26 \pm 0.16$ & 25 \\
\hline $\begin{array}{l}\text { Eurytemora affinis } \\
\text { (females) }\end{array}$ & $5.42 \pm 6.74$ & $5.51 \pm 2.51$ & $0.34 \pm 0.17$ & 28 \\
\hline $\begin{array}{l}\text { Pseudocalanus elongatus } \\
\text { (adults) }\end{array}$ & $10.40 \pm 12.29$ & $4.31 \pm 1.65$ & $0.33 \pm 0.21$ & 16 \\
\hline $\begin{array}{l}\text { Temora longicornis } \\
\text { (adults) }\end{array}$ & $14.19 \pm 12.93$ & $4.69 \pm 1.75$ & $0.51 \pm 0.29$ & 29 \\
\hline
\end{tabular}

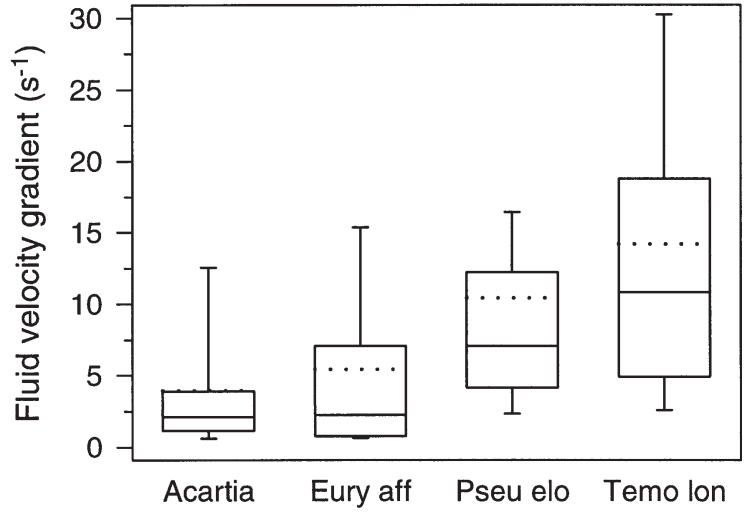

Fig. 5. Zooplankton escape experiment with artificial flow, showing fluid-velocity gradients $\left(\mathrm{s}^{-1}\right)$ that elicited an escape reaction in Acartia sp., Eurytemora affinis, Pseudocalanus elongatus, and Temora longicornis. Data correspond to escape locations below opening of the pipette (see Fig. 4). Small threshold value indicates escape further away from the pipette than a large threshold value. Ends of boxes: 25th and 75th percentiles; ends of whiskers: 10th and 90th percentiles of the data; middle horizontal lines: medians; dotted lines: averages

A more detailed inspection of the video films showed that Eurytemora affinis often first performed several small escape jumps and then finally released themselves from the flow with a very strong jump. Also, Temora longicornis could escape to a relatively long total distance (mean $0.51 \mathrm{~cm}$; Table 2) compared to the other copepods $(0.26$ to $0.34 \mathrm{~cm})$. In contrast, the 'alert' Acartia sp. performed the weakest escape jump (initial speed $4.05 \mathrm{~cm} \mathrm{~s}^{-1}$, total distance $0.26 \mathrm{~cm}$ ), and was often repeatedly entrained in the flow. Consequently, the final siphon capture success was clearly higher (33\%) for Acartia sp. than for E. affinis (9\%; Table 3). Pseudocalanus elongatus also exhibited a weak escape response and was often captured immediately or after 1 to 3 escapes (siphon capture success $86 \%$ ). Bosmina longispina maritima was never seen to escape (siphon capture success 100\%). In summary, the siphon capture success ranking was $B$. longispina maritima $>P$. elongatus $>T$. longicornis $>$ Acartia sp. $>$ E. affinis (Table 3).

\section{Herring and mysid selectivities versus siphon selectivity}

We also evaluated the selectivity patterns in herring and mysids by plotting selectivities of the 2 predator species against siphon selectivity. The plot of the herring selectivity rank against the 
Table 3. Summary table of mean selectivity indices, $V$, and selectivity rank for herring (Clupea harengus membras) and mysids (Mysis mixta), and siphon capture success of 'prey' in experiments with artificial flow. For herring and M. mixta, a high rank (4 or 5) indicates positive selection, a low rank (1 or 2) rejection. Siphon capture success is shown as percentage, with number of interactions in parentheses (see 'Materials and methods' for explanation)

\begin{tabular}{|c|c|c|c|c|c|c|}
\hline \multirow[t]{2}{*}{ Species (stage) } & \multicolumn{2}{|c|}{ Herring } & \multicolumn{2}{|c|}{ M. mixta } & \multicolumn{2}{|c|}{ Siphon capture success } \\
\hline & $V$ & Rank & $V$ & Rank & $\%$ & Rank \\
\hline Acartia sp. (adults) & -0.075 & 2 & -0.050 & 1 & $33(49)$ & 2 \\
\hline Eurytemora affinis (adults/females ${ }^{\mathrm{a}}$ ) & 0.078 & 4 & 0.025 & 4 & $9(56)$ & 1 \\
\hline Pseudocalanus elongatus (adults/copepodites ${ }^{\mathrm{b}}$ ) & 0.028 & 3 & 0.006 & 2 & $86(29)$ & 4 \\
\hline Temora longicornis (adults) & 0.198 & 5 & 0.038 & 5 & $74(50)$ & 3 \\
\hline Bosmina longispina maritima (females) & -0.080 & 1 & 0.012 & 3 & $100(21)$ & 5 \\
\hline
\end{tabular}

siphon selectivity rank showed no correlation (Fig. 6A). Notably, Bosmina longispina maritima, that showed no escape response, was clearly rejected by herring (Rank 1), whereas the evasive Eurytemora affinis was strongly positively selected (Rank 4). Similarly, Mysis mixta selectivity did not correspond with siphon selectivity: E. affinis again had a high rank 4 (Fig. 6B). Finally, plotting $M$. mixta selectivity rank against that of herring (Fig. 6C) showed that, for copepods, the ranking was exactly the same. In contrast, the cladoceran $B$. longispina maritima was the least selected by herring but ranked third for the mysids.

\section{DISCUSSION}

\section{Prey selection}

In planktivorous predatory interactions, prey vulnerability should peak at intermediate prey sizes because prey escape capabilities usually increase with increasing prey size (Pastorok 1981, Greene 1988). However, we did not detect any hump in the prey vulnerability data for Clupea harengus membras (Fig. 1). This implies that, within the prey size range studied, herring did not have a threshold prey size above which the prey would be too difficult to catch. We can therefore maintain the hypothesis of a positive relationship between prey body size and herring selectivity. A sizeselective tendency of herring, also demonstrated by earlier findings (Sandström 1980, Checkley 1982), is plausible since the largest prey are detected from the longest distance, which rapidly enlarges the volume of water the fish can clear from large prey (cf. Gerritsen \& Strickler 1977). For the mysids, the selectivity data in Fig. 2 conforms better with the non-linear hypothesis (Pastorok 1981). This may indicate that the largest prey were close to the upper threshold of prey sizes available for Mysis mixta. It must however be noted that the
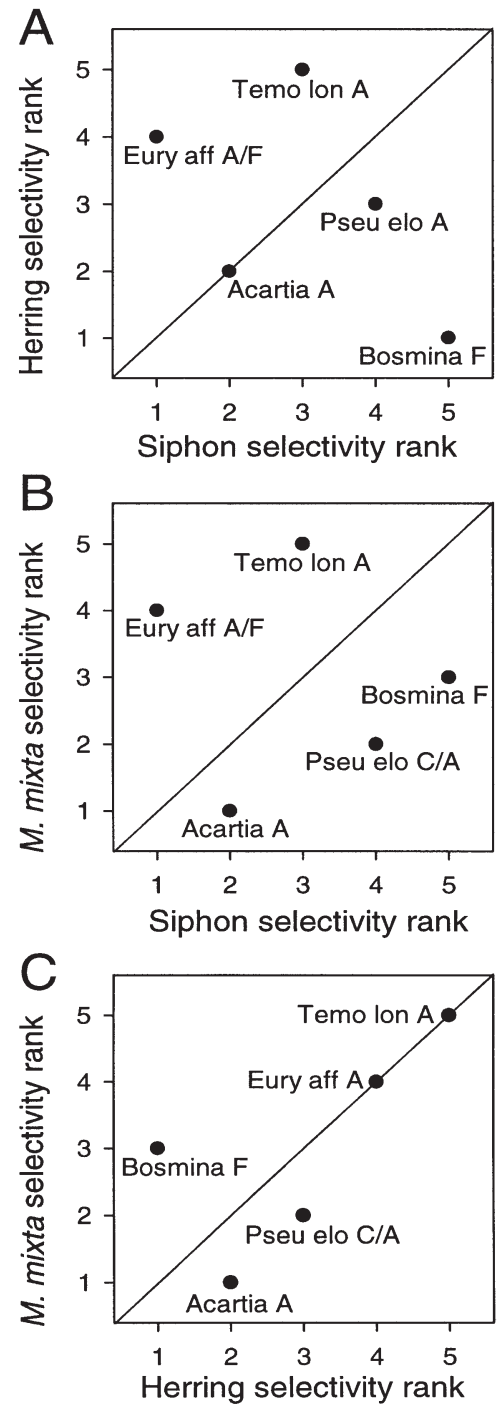

Fig. 6. Prey selectivity ranks of (A) Clupea harengus membras and (B) Mysis mixta, plotted against siphon selectivity ranks, and (C) plotted against each other. Rank data from Table 3; diagonal line represents the 1:1 line. A: adult; C: copepodite; F: female; species abbreviations as in Fig. 1 
wet weight of copepods in the study area may vary seasonally by almost a factor of 2 (Viitasalo et al. 1995a). This may make the results for mysid selectivity more uncertain.

The size-selective tendency of Mysis mixta was evident in the case of 4 copepod prey (Acartia sp., Eurytemora affinis, Pseudocalanus elongatus and Temora longicornis; see Figs. 2 \& 6). This could be due to mysid using vision in prey detection; at least Ramcharan \& Sprules (1986) have shown that freshwater mysids are able to capture more prey in light than in darkness. However, our own recent experiments (Viherluoto \& Viitasalo 2001b) have shown that Baltic M. mixta do not increase their feeding rates in the light. Thus we suggest that the selectivity of both herring and $M$. mixta is based on prey size, but that it is mediated by different mechanisms, i.e. visual cues in herring and hydromechanical cues in mysids.

There were clear differences in the escape capabilities of the zooplankton species, which partly explain the observed selectivities by herring and mysids. We thus interpret our results concerning the 5 most abundant prey species in the following way: Baltic herring preys preferentially on the largest and most conspicuous prey items, such as Eurytemora affinis females and Temora longicornis, and egg-carrying cladocerans (Fig. 1). The delayed escape response of T. longicornis (Fig. 5) also makes it an easy prey, and it was consequently the most positively selected species by both herring and mysids. Acartia sp., in turn, were negatively selected, probably because of their relatively small size and their alertness to hydrodynamic signals. The same conclusion was reached by Checkley (1982) for Clupea harengus larvae, which preferred Pseudocalanus sp. to the evasive Acartia sp. In contrast, the fact that the agile $E$. affinis adults were more positively selected than predicted by their size (Table 1) implies a 'true' selection by herring, whereas the negative selection by herring on the poorly escaping, relatively large-sized Pseudocalanus elongatus indicates 'true rejection'.

\section{Predation-avoidance strategies}

The 5 zooplankton species that we tested against the siphon flow showed different escape behaviours. Two species, Acartia sp. and Eurytemora affinis, were relatively alert, while Temora longicornis was less alert but attempted to escape by a strong leap. The early escape response of Acartia sp. can be explained by the conspicuous setae on its first antennae, which are used for hydrodynamic detection of ciliates and small rotifers (Stoecker \& Egloff 1987, Jonsson \& Tiselius 1990). This 'sensitivity strategy', whereby a plankter escapes from a relatively long distance from a predator, allows a lower escape speed than in the less sensitive species. This however does not explain why the short-setae $E$. affinis was the best escaper, and other factors need to be evoked. Notably, E. affinis females carry large egg sacs containing up to 30 eggs. Thus, when encountering a predator, the female has more at stake than its own life, which may promote the evolution of strong escape responses. The other egg-carrying calanoid species in the Baltic Sea, Pseudocalanus elongatus, carries much smaller eggs sacs, which are also very easily detached from the female (M.V. pers. obs.). This conforms to its weaker escape capabilities compared to E. affinis. The egg-carrying cladocerans, in turn, show a very rapid parthenogenetic reproduction and can thus numerically outgrow their predators. They therefore need not possess as strong escape capabilities as copepods.

\section{Field implications}

One of our objectives was to estimate the effect of changes in zooplankton communities on food availability for Baltic planktivores. Several studies have shown that the populations of certain zooplankton species vary according to fluctuations in Baltic Sea hydrography. For instance, abundances of Bosmina longispina maritima and Eurytemora affinis have been shown to increase during periods of low salinity (Viitasalo et al. 1994, Viitasalo et al. 1995b), whereas high abundances of the neritic copepods (mainly Pseudocalanus elongatus and Temora longicornis) have been associated with elevated salinity (Vuorinen \& Ranta 1987, Lumberg \& Ojaveer 1991, Viitasalo et al. 1995b, Vuorinen et al. 1998). Based on the results of the present study, we can rank the 5 most abundant zooplankton taxa in the northern Baltic according to their 'profitability' for Baltic planktivores: T. longicornis $>$ E. affinis $>P$. elongatus $>B$. longispina maritima $>$ Acartia sp. We hypothesise that if Baltic salinity declines the food conditions of herring deteriorate. This supports the findings of Flinkman et al. (1998), who found that the weight-at-age of the northern Baltic herring declined by $50 \%$ during a low-salinity period dominated by $B$. longispina maritima. How an increase in the positively selected $E$. affinis would affect the food avoidability for herring, would depend on the age and size (i.e. predatory capabilities) of the herring, with large fish benefiting more than their smaller conspecifics. For the mysids, the consequences of changes in prey assemblages are harder to predict. A decrease in T. longicornis would be a disadvantage, whereas an increase in the easily predated cladocerans might be favourable. However, the semibenthic, 
omnivorous habits of mysids may compensate for any negative changes in zooplankton availability.

Acknowledgements. This study was financed by the Academy of Finland and the Walter and Andrée de Nottbeck Foundation. We gratefully acknowledge E. Aro (Finnish Game and Fisheries Research Institute) for initiating the herring selectivity study in the Archipelago Sea. We also thank T. Sjölund for help in the field and the Danish Institute for Fisheries Research and M. Lindström (University of Helsinki) for providing some of the video equipment. Thoughtful comments by T. Kiørboe, H. Salemaa, I. Vuorinen and 3 anonymous referees are also gratefully acknowledged.

\section{LITERATURE CITED}

Aebischer NJ, Coulson JC, Colebrook JM (1990) Parallel long-term trends across four marine trophic levels and weather. Nature 347:753-755

Barnhisel DR (1991) The caudal appendage of the cladoceran Bythotrepes cederstroemi as defense against young fish. J Plankton Res 13:529-537

Blaxter JHS, Hunter JR (1982) The biology of clupeoid fishes. Adv Mar Biol 20:1-223

Boyd CM (1976) Selection of particle sizes by filter-feeding copepods: a plea for reason. Limnol Oceanogr 21:175-180

Brooks JL, Dodson SI (1965) Predation, body size, and composition of plankton. Science 150:28-35

Browman HI, Kruse S, O’Brien WJ (1989) Foraging behavior of the predaceous cladoceran, Leptodora kindti, and escape responses of their prey. J Plankton Res 11: 1075-1088

Buskey EJ (1994) Factors affecting feeding selectivity of visual predators on the copepod Acartia tonsa: locomotion, visibility and escape responses. Hydrobiologia 292/293: 447-453

Checkley DM (1982) Selective feeding by Atlantic herring (Clupea harengus) larvae on zooplankton in natural assemblages. Mar Ecol Prog Ser 9:245-253

Chesson J (1978) Measuring preference in selective predation. Ecology 9:923-947

Dodson SI (1974) Adaptive change in plankton morphology in response to size-selective predation: a new hypothesis of cyclomorphosis. Limnol Oceanogr 19:721-729

Drenner RW, Strickler JR, O'Brien WJ (1978) Capture probability: the role of zooplankter escape in the selective feeding of planktivorous fish. J Fish Res Board Can 35: 1370-1373

Drost MR, Osse JWM, Muller M (1988) Prey capture by fish larvae, water flow patterns and the effect of escape movements of prey. Neth J Zool 38:23-45

Flinkman J, Vuorinen I, Aro E (1992) Planktivorous Baltic herring (Clupea harengus) prey selectively on reproducing copepods and cladocerans. Can J Fish Aquat Sci 49:73-77

Flinkman J, Aro E, Vuorinen I, Viitasalo M (1998) Changes in northern Baltic zooplankton and herring nutrition from 1980s to 1990s: top-down and bottom-up processes at work. Mar Ecol Prog Ser 165:127-136

Fransz HG, Colebrook JM, Gamble JC, Krause M (1991) The zooplankton of the North Sea. Neth J Sea Res 28:1-52

Gardner MB (1981) Mechanisms of size selectivity by planktivorous fish: a test of hypotheses. Ecology 62:571-578

Gerritsen J, Strickler JR (1977) Encounter probabilities and community structure in zooplankton: a mathematical model. J Fish Res Board Can 34:73-82
Greene CH (1988) Foraging tactics and prey-selection patterns of omnivorous and carnivorous calanoid copepods. In: Boxshall GA, Schminke HK (eds) Biology of copepods. Kluwer Academic Publishers, Dordrecht, p 295-302

Heath MR (1993) The role of escape reactions in determining the size distribution of prey captured by herring larvae. Environ Biol Fish 38:331-344

Hernroth L (1985) Recommendations on methods for marine biological studies in the Baltic Sea. Mesozooplankton biomass assessment. Balt Mar Biol Publ 10:1-32

Holling CS (1959) The components of predation as revealed by a study of small-mammal predation of the European pine sawfly. Can Entomol 91:293-320

Jonsson PR, Tiselius P (1990) Feeding behaviour, prey detection and capture efficiency of the copepod Acartia tonsa feeding on planktonic ciliates. Mar Ecol Prog Ser 60: $35-44$

Kerfoot WC (1978) Combat between predatory copepods and their prey: Cyclops, Epischura, and Bosmina. Limnol Oceanogr 23:1089-1102

Lechowicz MJ (1982) The sampling characteristics of electivity indices. Oecologia 52:22-30

Lumberg A, Ojaveer E (1991) On the environment and zooplankton dynamics in the Gulf of Finland in 1961-1990. Proc Est Acad Sci Ecol 1:131-140

Luo J, Brandt SB, Klebasko MJ (1996) Virtual reality of planktivores: a fish's perspective of prey size selection. Mar Ecol Prog Ser 140:271-283

Mauchline J (1980) The biology of mysids and euphausiids. Adv Mar Biol 18:1-677

O'Brien WJ, Slade NA, Vinyard GL (1976) Apparent size as the determinant of prey selection by bluegill sunfish (Lepomis macrochirus). Ecology 57:1304-1310

Pastorok RA (1981) Prey vulnerability and size selection by Chaoborus larvae. Ecology 62:1311-1324

Pearre S (1982) Estimating prey preference by predators: uses of various indices, and a proposal of another based on $\chi^{2}$. Can J Fish Aquat Sci 39:914-923

Ramcharan CW, Sprules WG (1986) Visual predation in Mysis relicta Lovén. Limnol Oceanogr 31:414-420

Rudstam LG, Danielsson K, Hansson S, Johansson S (1989) Diel vertical migration and feeding patterns of Mysis mixta (Crustacea, Mysidacea) in the Baltic Sea. Mar Biol 101:43-52

Sandström O (1980) Selective feeding by Baltic herring Hydrobiologia 69:199-207

Segerstråle SG (1969) Biological fluctuations in the Baltic Sea. Prog Oceanogr 5:169-184

Singarajah KV (1969) Escape reactions of zooplankton: the avoidance of a pursuing siphon tube. J Exp Mar Biol Ecol 3:171-178

Stoecker DK, Egloff DA (1987) Predation by Acartia tonsa Dana on planktonic ciliates and rotifers. J Exp Mar Biol Ecol 110:53-68

Strickler JR (1975) Intra- and interspecific information flow among planktonic copepods: receptors. Verh Int Verein Limnol 19:2951-2958

Suchman CL, Sullivan BK (1998) Vulnerability of the copepod Acartia tonsa to predation by the scyphomedusa Chrysaora quinquecirrha: effect of prey size and behavior. Mar Biol 132:237-245

Tiselius P, Jonsson PR, Kaartvedt S, Olsen EM, Jorstad T (1997) Effects of copepod foraging behavior on predation risk: an experimental study of the predatory copepod Paraeuchaeta norvegica feeding on Acartia clausi and A. tonsa (Copepoda). Limnol Oceanogr 42:164-170

Tsuda A, Saito H, Hirose T (1998) Effect of gut content on 
the vulnerability of copepods to visual predation. Limnol Oceanogr 43:1944-1947

Viherluoto M, Viitasalo M (2001a) Temporal variability in functional responses and prey selectivity of the pelagic mysid, Mysis mixta, in natural prey assemblages. Mar Biol 138:575-583

Viherluoto M, Viitasalo M (2001b) Effect of light on the feeding rates of pelagic and littoral mysid shrimps: a trade-off between feeding success and predation avoidance. J Exp Mar Biol Ecol 261:237-244

Viherluoto M, Kuosa H, Flinkman J, Viitasalo M (2000) Food utilisation of pelagic mysids, Mysis mixta and M. relicta, during their growing season in the northern Baltic Sea. Mar Biol 136:553-559

Viitasalo M (1992) Mesozooplankton of the Gulf of Finland and northern Baltic Proper-a review of monitoring data. Ophelia 35:147-168

Viitasalo M, Rautio M (1998) Zooplanktivory by Praunus flexuosus (Crustacea: Mysidacea): functional responses and prey selection in relation to prey escape responses. Mar Ecol Prog Ser 174:77-87

Viitasalo M, Katajisto T, Vuorinen I (1994) Seasonal dynamics of Acartia bifilosa and Eurytemora affinis (Copepoda: Calanoida) in relation to abiotic factors in the northern Baltic Sea. Hydrobiologia 292/293:415-422

Viitasalo M, Koski M, Pellikka K, Johansson S (1995a) Seasonal and long-term variations in the body size of planktonic copepods in the northern Baltic Sea. Mar Biol 123: 241-250

Viitasalo M, Vuorinen I, Saesmaa S (1995b) Mesozooplankton dynamics in the northern Baltic Sea: implications of variations in hydrography and climate. J Plankton Res 17: 1857-1878

Viitasalo M, Kiørboe T, Flinkman J, Pedersen LW, Visser AW

Editorial responsibility: Otto Kinne (Editor),

Oldendorf/Luhe, Germany
(1998) Predation vulnerability of planktonic copepods: consequences of predator foraging strategies and prey sensory abilities. Mar Ecol Prog Ser 175:129-142

Vuorinen I, Ranta E (1987) Dynamics of marine mesozooplankton at Seili, Northern Baltic Sea, in 1967-1975. Ophelia 28:31-48

Vuorinen I, Hänninen J, Viitasalo M, Helminen U, Kuosa H (1998) Proportion of copepod biomass declines with decreasing salinity in the Baltic Sea. ICES J Mar Sci 55: $767-774$

Wetterer JK (1989) Mechanisms of prey choice by planktivorous fish: perceptual constraints and rules of thumb. Anim Behav 37:955-967

Williamson CE (1980) The predatory behaviour of Mesocyclops edax: predator preferences, prey defenses, and starvation-induced changes. Limnol Oceanogr 25: 903-909

Yen J, Fields DM (1992) Escape responses of Acartia hudsonica (Copepoda) nauplii from the flow field of Temora longicornis (Copepoda). Arch Hydrobiol Spec Issues (Ergeb Limnol) 36:123-134

Yen J, Strickler JR (1996) Advertisement and concealment in the plankton: what makes a copepod hydrodynamically conspicuous? Invertebr Biol 115:191-205

Zaret TM (1972) Predators, invisible prey, and the nature of polymorphism in the Cladocera (class Crustacea). Limnol Oceanogr 17:171-184

Zaret TM (1980) The effect of prey motion on planktivore choice. In: Kerfoot WC (ed) Evolution and ecology of zooplankton communities. Univ Press New England, Hanover, NH, p 594-603

Zaret TM, Kerfoot C (1975) Fish predation on Bosmina longirostris: body-size selection versus visibility selection. Ecology 56:232-237

Submitted: July 25, 2000; Accepted: November 9, 2000

Proofs received from author(s): June 22. 2001 